\title{
Regularities of the Formation of a Green Superhydrophobic Protective Coating on an Aluminum Alloy after Surface Modification with Stearic Acid Solutions
}

\author{
Aleksey Abrashov ${ }^{1, *(D)}$, Nelya Grigoryan ${ }^{1}$, Yuri Korshak ${ }^{1}$, Tigran Vagramyan ${ }^{1}$, Oleg Grafov ${ }^{2}$ (D) \\ and Yaroslav Mezhuev ${ }^{1}$ \\ 1 Mendeleev University of Chemical Technology of Russia, 125047 Moscow, Russia; \\ ngrigoryan@muctr.ru (N.G.); yukorshak@yandex.ru (Y.K.); vagramyan@muctr.ru (T.V.); \\ valsorja@mail.ru (Y.M.) \\ 2 A.N. Frumkin Institute of Physical Chemistry and Electrochemistry of the Russian Academy of Sciences, \\ 119071 Moscow, Russia; grafov.oleg88@gmail.com \\ * Correspondence: aabrashov@muctr.ru; Tel.: +7-499-978-94-51
}

Citation: Abrashov, A.; Grigoryan, N.; Korshak, Y.; Vagramyan, T.; Grafov, O.; Mezhuev, Y. Regularities of the Formation of a Green Superhydrophobic Protective Coating on an Aluminum Alloy after Surface Modification with Stearic Acid Solutions. Metals 2021, 11, 1718. https://doi.org/10.3390/ met11111718

Academic Editors: Belén Díaz Fernández and Guosong Wu

Received: 18 September 2021

Accepted: 23 October 2021

Published: 27 October 2021

Publisher's Note: MDPI stays neutral with regard to jurisdictional claims in published maps and institutional affiliations.

Copyright: (c) 2021 by the authors. Licensee MDPI, Basel, Switzerland. This article is an open access article distributed under the terms and conditions of the Creative Commons Attribution (CC BY) license (https:// creativecommons.org/licenses/by/ $4.0 /)$

\begin{abstract}
It has been shown that solutions of stearic acid in a dimethyl sulfoxide-water binary mixture allow superhydrophobic protective coatings to be created on an aluminum alloy surface with a minimum impact on the environment. The superhydrophobicity and self-cleaning ability of the coating that we developed have been confirmed by measurements of droplet wetting angles and roll-off angles. These properties appear due to the formation of a multimodal micro-rough surface that mainly consists of aluminum stearate. The coatings formed in this manner have been studied by ellipsometry, XPS, and scanning probe microscopy. Their protective ability has been estimated by the "droplet-express" method and in a salt fog chamber. The protective ability of the coating is determined by the DMSO $/ \mathrm{H}_{2} \mathrm{O}$ ratio, the concentration of stearic acid, and the duration and temperature of modification of the aluminum alloy; it is controlled by a competition between the processes of aluminum stearate formation and hydrolysis. It has been shown that adsorption of stearic acid on an aluminum stearate coating increases its permeability and decreases its protective capability. The results presented in this article are useful for optimizing the conditions of applying green superhydrophobic stearate coatings on aluminum alloys in order to achieve a maximum protective effect.
\end{abstract}

Keywords: superhydrophobic materials; corrosion protection; protection of aluminum alloys; stearic acid; aluminum passivation

\section{Introduction}

Materials with a water wetting angle above $150^{\circ}$, with a droplet roll-off angle below $10^{\circ}$, and a pronounced surface self-cleaning capability, are classified as superhydrophobic [1-4]. Superhydrophobicity underlies the self-cleaning of surfaces in some plants and insects [3-7] and is often required in the formation of anti-corrosion, anti-fouling, and anti-icing coatings [8-19] as well as for the production of pollution-resistant textile materials [20].

Some materials, including aluminum and its alloys, are subject to oxidation in air that produces an oxide film whose protective properties are sometimes insufficient. Therefore, the creation of continuous superhydrophobic self-cleaning films on the surfaces of aluminum and its alloys could be an in-demand alternative $[6,8,21-23]$ to passivation with solutions of $\mathrm{Cr}(\mathrm{VI})$ compounds that manifest considerable toxicity. However, superhydrophobization requires a surface with multimodal roughness to be formed beforehand to enable the transition from the Wenzel state to the Cassie state, followed by modification with agents that reduce surface energy [3,24-28]. Anodizing [29,30], chemical vapor deposition [6,8], sol-gel technology [31-33], and laser treatment [34,35] are used to impart 
multimodal roughness onto a surface. Long-chain alkyl and perfluoroalkyl chains are functionalized with a group that allows them to be affixed to the surface and are used as agents with low surface energy. Fluoroalkylsilanes, octadecyltrimethoxysilane, tetradecanoic acid, stearic acid, copolymers of styrene, and STYPHOS acid are used as compounds of this type [36,37]. Despite the significant progress in the use of superhydrophobic coatings, the regularities of variation in their protective ability depending on the production conditions are not quite clear yet. In addition, the majority of hydrophobization methods employ toxic agents at the stage of relief formation or surface modification, which creates risks of increasing the impact on the environment. Therefore, this article is aimed at the development of green superhydrophobic coatings and the determination of the regularities of variation in their protective ability depending on the conditions of layer formation on the surface of AMg6 aluminum alloy.

\section{Materials and Methods}

\subsection{Aluminum Alloy Hydrophobization}

Aluminum alloy AMg6 was used in the experiments. Its composition is as follows (\%): Al 91.1-93.68; Mg 5.8-6.8; Mn 0.5-0.8. It was manufactured by Degtyarsky Metallurgical Plant LLC (Degtyarsk, Russia). The samples, shaped as rectangular plates with dimensions of $30 \times 40 \times 1 \mathrm{~mm}$, were machined to reach a "mirror" gloss. The samples were degreased in a solution containing (g/L): $\mathrm{Na}_{3} \mathrm{PO}_{4} \cdot 12 \mathrm{H}_{2} \mathrm{O} 22 ; \mathrm{Na}_{2} \mathrm{CO}_{3} 25 ; \mathrm{NaOH} 7.5 ; \mathrm{Na}_{2} \mathrm{SiO}_{3}$ 10; DS104 , at $60-70{ }^{\circ} \mathrm{C}$ for $10 \mathrm{~min}$ [38]. The roughness on the alloy surface was created by etching in $10 \% \mathrm{NaOH}$ solution for $30 \mathrm{~s}$ at $70{ }^{\circ} \mathrm{C}[6,38]$. Stearic acid with purity higher than $95 \mathrm{wt} \%$ (Sigma Aldrich, Taufkirchen, Germany) was used as the hydrophobizing agent. Stearic acid was dissolved in a binary system obtained by mixing preset amounts of dimethyl sulfoxide (DMSO, purity higher than $99 \mathrm{wt} \%$ ) and distilled water. After hydrophobization, the samples were dried at $80^{\circ} \mathrm{C}$ for $10 \mathrm{~min}$.

\subsection{Determination of the Coating Protective Capability}

A droplet of a solution containing: $\mathrm{CuSO}_{4} \cdot 5 \mathrm{H}_{2} \mathrm{O} 82 \mathrm{~g} / \mathrm{L} ; \mathrm{NaCl} 33 \mathrm{~g} / \mathrm{L} ; 0.1 \mathrm{~N} \mathrm{HCl}$ $13 \mathrm{~mL} / \mathrm{L}$ was applied to a plate, and the time required for the plate color to change from gray to black was measured [39,40].

Corrosion tests were carried out in an Ascott S450iP salt spray chamber (UK), (Ascott Analytical Equipment Ltd., Tamworth, UK) in accordance with ASTM B117. The salt solution contained $5 \% \mathrm{NaCl}(\mathrm{pH} 6.5-7.2)$. It was sprayed inside the chamber with the test samples. The temperature in the chamber was $35^{\circ} \mathrm{C}$ and the humidity was $95-100 \%$. The samples were examined three times a day to detect the formation of the first corrosion sites. The surface morphology of the samples before and after exposure to salt fog was investigated on a LEXT-OSL 4100 confocal laser microscope (OLYMPUS Corporation, Tokyo, Japan) equipped with an MPLAPONLEXT 100 camera lens (OLYMPUS Corporation, Tokyo, Japan).

\subsection{Determination of the Coating Thickness}

To determine the thickness of the coatings with a Sentech SENreseach 4.0 SER 800 ellipsometer (SENTECH Instruments GmbH, Krailling, Germany) equipped with a high-speed monochromator, we recorded the plots of ellipsometric parameters $\Psi$ and $\Delta$ versus wavelengths in the spectral range from 240 to $1000 \mathrm{~nm}$ with a goniometer angle of $70^{\circ}$. A three-layer model, including two Drude-Lorentz layers and one Cauchy layer, was used for the calculations. The parameters of the model (thickness $d$, refractive index $n 2$ ) based on the measured $\Psi$ and $\Delta$ values (the so-called inverse ellipsometry problem) were determined by the software of the instrument in accordance with the mathematical model selected [41]. 


\subsection{Determination of the Coating Composition by XPS}

The composition of surface layers was determined by XPS (Omicron, Taunusstein, Germany). Coated samples were mounted in a holder and placed into the pre-evacuation chamber of the OMICRON ESCA + XPS setup (Omicron). The samples were then transferred to the analyzer chamber where a pressure no higher than $8 \times 10^{-10}$ mbar was maintained. $\mathrm{MgK} \alpha$ radiation (1253.6 eV; $252 \mathrm{~W}$ power) was used. The analyzer's pass energy was $20 \mathrm{eV}$. To account for the sample charging, the positions of XPS peaks were standardized relative to the $\mathrm{C} 1 \mathrm{~s}$ peak of the hydrocarbon impurities from the atmosphere. The binding energy Eb of the peak was taken to be $285.0 \mathrm{eV}$. The spectra were deconvoluted after background subtraction by the Shirley method [42]. The peak positions were determined with an accuracy of $\pm 0.1 \mathrm{eV}$. The component ratios were calculated using the integrated intensities under the peaks, taking the photoionization cross sections $\sigma$ of the corresponding electron shells into account [43]. Based on the integral intensity of the peaks and using MultiQuant software (version 7, Research Laboratory of Materials and Environmental Chemistry, Chemical Research Center, Hungarian Academy of Sciences, Budapest, Hungary) [44], the thicknesses of the layers formed on the surface were calculated with consideration for the mean free path of electrons $\lambda$ determined by the Cumpson and Cumpson-Seah formula [45]. Analysis of the spectra obtained was performed under the assumption that the analyzing beam penetrates the material to a depth of $5 \mathrm{~nm}$, i.e., the recorded spectra correspond to a $5 \mathrm{~nm}$-thick layer of the material [46].

\subsection{Determination of Morphology, Roughness, and Wetting Angle}

The morphological studies of the coating surfaces and determination of their roughness were carried out using a Solver Pro scanning probe microscope (NT-MDT, Russia, Zelenograd).

The wetting angle of surface wetting with water was determined using a Goniometer LK-1 device (OpenScience, Krasnogorsk, Russia). For this purpose, a Levenchuk C310 NG camera (Levenhuk, Tampa, FL, USA) was used to obtain photo images of the droplets and then the angle was determined using special DropShape software developed at the Colloid Chemistry Department of the M.V. Lomonosov Moscow State University, Russia, version 3.

\subsection{Determination of the Wear Resistance of the Coating}

The wear resistance of the coatings was examined on a Taber Elcometer 5135 modified rotation abrasimeter (Elcometer Limited, Manchester, UK). Planar samples with coatings were attached to the levers of the installation and pressed against a felt disk at the same external load on both the levers of $3.5 \mathrm{~N} \times \mathrm{cm}^{-2}$. The samples were abraded by rotating the felt disk at a speed of $60 \mathrm{rpm}$. The abrasion resistance of the samples was assessed by the decrease in the coating thickness, the contact angle, and the protective effect of the stearate layer with the increase in the number of disk revolutions. The protective effect, the thickness, and the contact angle of the coating were determined as described in Section 2.2, Section 2.3, and Section 2.5, respectively.

\section{Results and Discussion}

It may be assumed that, on treatment of $\mathrm{AMg} 6$ alloy surface in air with a solution of stearic acid in the DMSO $/ \mathrm{H}_{2} \mathrm{O}$ binary solvent system, aluminum stearate is predominantly formed on the surface. It is ultimately responsible for the hydrophobization effect achieved. Although DMSO is less basic with respect to carboxylic acids than water [47], its presence provides a sufficient solubility of stearic acid. Moreover, it may be expected that DMSO participates in the proton transfer from stearic acid to the metal surface. It is likely that the formation of a hydrophobic coating results from the sequence of steps shown in Scheme 1.

XPS data (Figure 1) agree with the reactions shown in Scheme 1 and indicate that the coating contains oxygen, carbon, and aluminum. The formation of aluminum carboxylates in the surface layer is confirmed by the presence of the peaks of O1s at $531.2 \mathrm{eV}$ and $\mathrm{C} 1 \mathrm{~s}$ at $288.4 \mathrm{eV}$ characteristic of oxygen and carbon atoms in the $\mathrm{COO}^{-}$anion [6] and the Al2p peak $(74.1 \mathrm{eV})$ that corresponds to $\mathrm{Al}^{3+}$ cations [48]. 


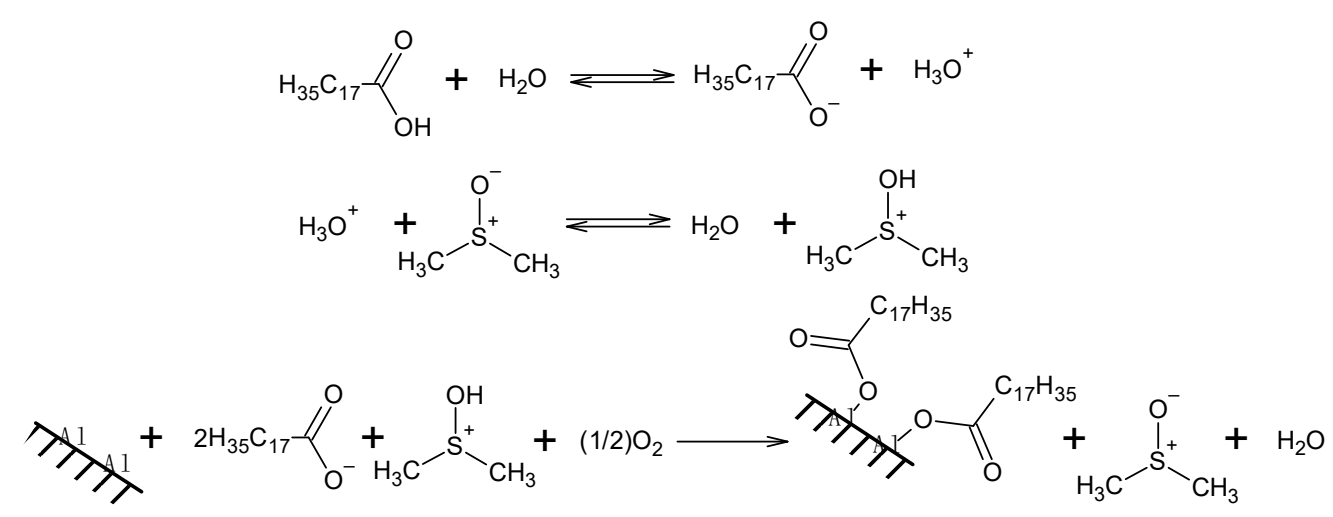

Scheme 1. Reactions that result in the formation of a hydrophobic stearate coating on the aluminum alloy surface.

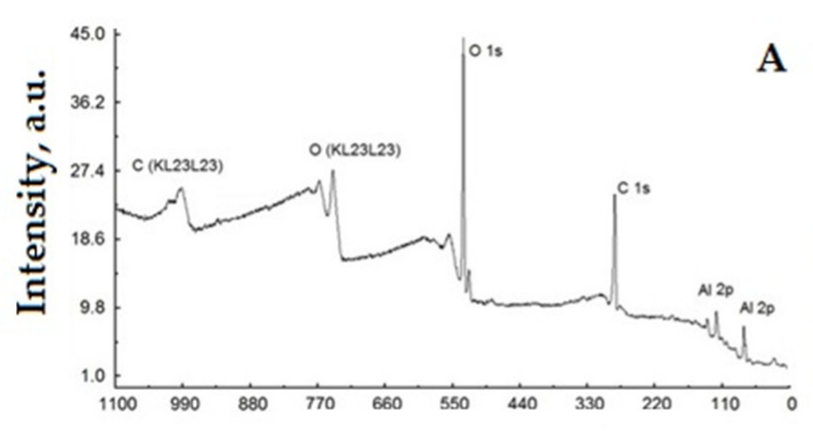

Binding energy, eV

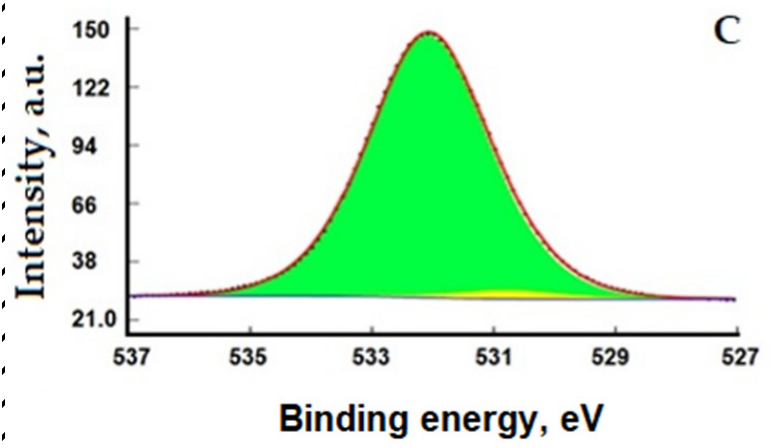

A
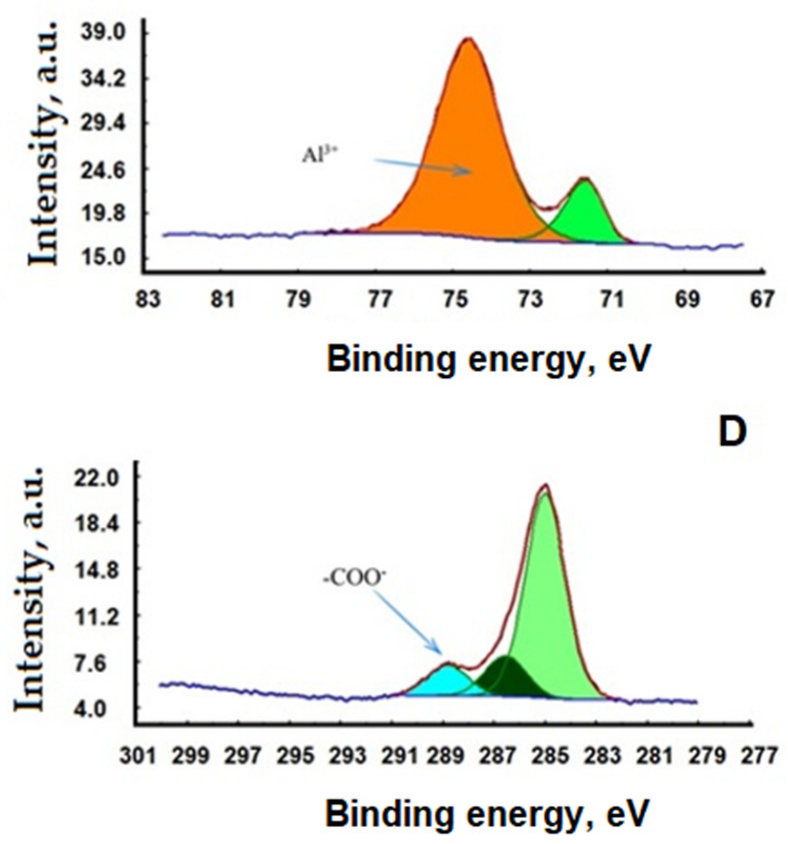

Figure 1. X-ray photoelectron spectra (XPS) of the coating: overview spectrum (A), aluminum (B), oxygen (C), carbon (D).

Since the formation of superhydrophobic coatings requires a surface morphology with a considerable roughness, micrographs and profile diagrams of the original degreased AMg6 alloy and surfaces formed after AMg6 etching in $10 \mathrm{wt} \%$ aqueous sodium hydroxide and after hydrophobization with a solution of stearic acid $\left(3 \mathrm{~g} \cdot \mathrm{L}^{-1}\right)$ in a DMSO $/ \mathrm{H}_{2} \mathrm{O}$ binary mixture $(7: 1 \mathrm{v} / \mathrm{v})$ at $40{ }^{\circ} \mathrm{C}$ for $10 \mathrm{~min}$ were obtained (Figure 2).

The initial mechanically treated sample of AMg6 alloy after degreasing had a wetting angle $(\theta \mathrm{w})$ of $15^{\circ}$ with an arithmetic mean roughness (Ra) of $0.798 \mu \mathrm{m}$. Subsequent etching in $10 \mathrm{wt} \%$ aqueous sodium hydroxide solution resulted in the dissolution of a fraction of the aluminum and increases in Ra to $0.889 \mu \mathrm{m}$ and $\theta \mathrm{w}$ to $44^{\circ}$. After hydrophobization with stearic acid, the surface roughness remained nearly unchanged $(\mathrm{Ra}=0.875 \mu \mathrm{m})$, which indicates that a uniform coating formed. At the same time, the wetting angle increased considerably to reach $151^{\circ}$, which allowed us to classify the coating formed on the surface of AMg6 alloy as superhydrophobic. The roll-off angle of a water droplet consistently decreased after hydrophobization from $100^{\circ}$ to $7^{\circ}$, which signified that the coating formed had a pronounced self-cleaning tendency. Micrographs (Figure 2) indicate that a rough surface with numerous microcavities over the entire area of the sample is formed after the 
etching stage and that this morphology is preserved after hydrophobization. Corrosion tests of AMg6 alloy with a hydrophobized surface in the salt fog chamber showed that the coating that we developed withstood $140 \mathrm{~h}$ until the first corrosion sites appeared on the substrate, while the natural oxide film provided protection for only $24 \mathrm{~h}$ (Figure 3). Thus, the protective ability of the hydrophobic coating formed is comparable to that achieved by applying chromate coatings (130-150 h) or anodic oxide coatings (96-120 h) $[29,30,38,49]$.
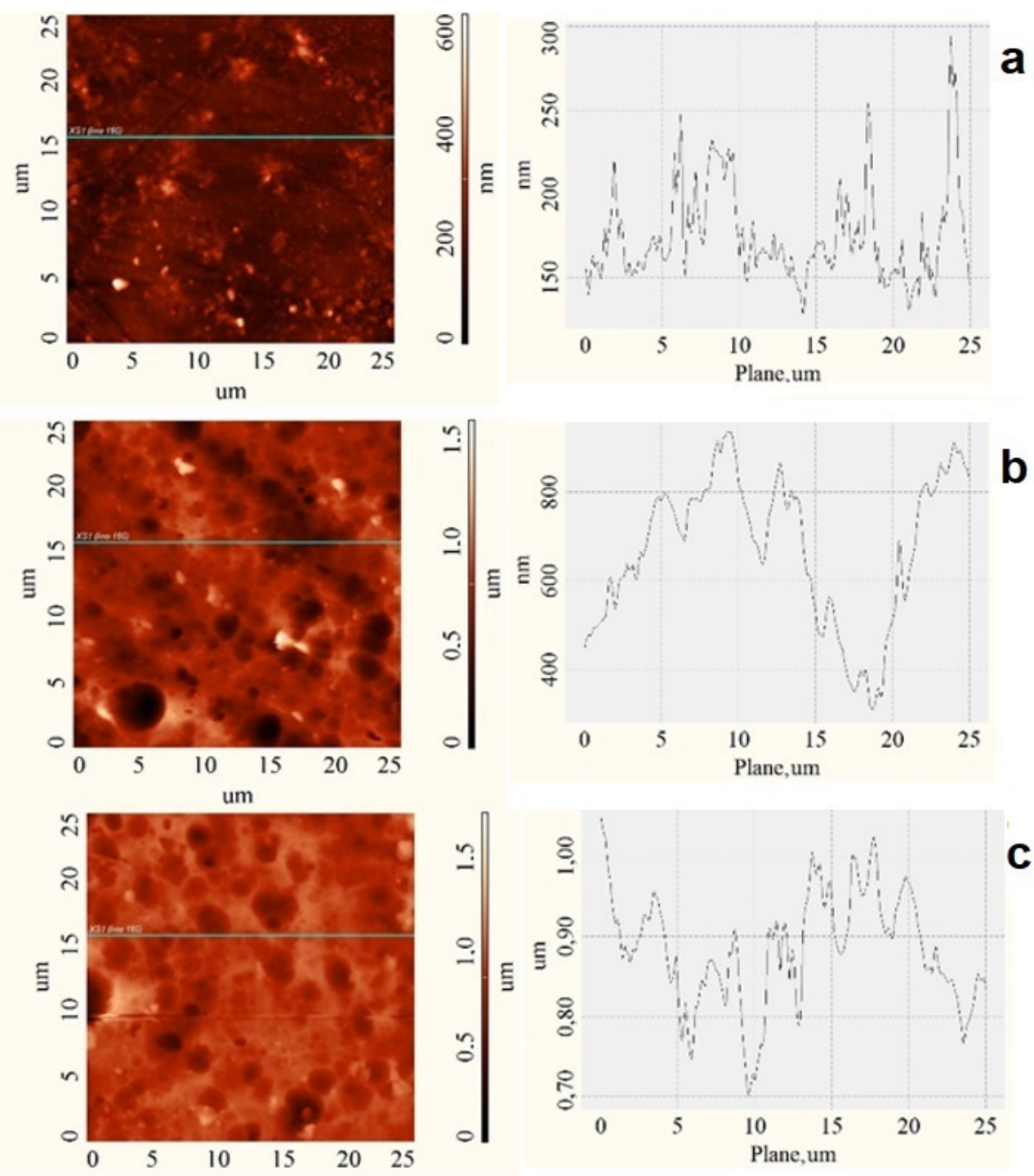

Figure 2. Photographs of the surface and profile diagrams of AMg6 alloy after degreasing (a), etching (b), and hydrophobization (c) stages [19].

Exposure to salt fog resulted in a gradual degradation of the hydrophobic protective coating, observed as a decrease in the wetting angle with time. It is noteworthy that the coating retains its hydrophobic properties for $80 \mathrm{~h}$, and only after that time, wetting inversion is observed (Figure 3). After exposure to salt fog, traces of focal corrosion appeared on the surface of the plates, which was clearly seen when comparing confocal micrographs of the samples before and after corrosion tests (Figure 4). Apparently, the corrosion of aluminum, accompanied by the formation of aluminum oxide and a change in the volume of the surface layer, leads to flaking and destruction of the stearate coating. 


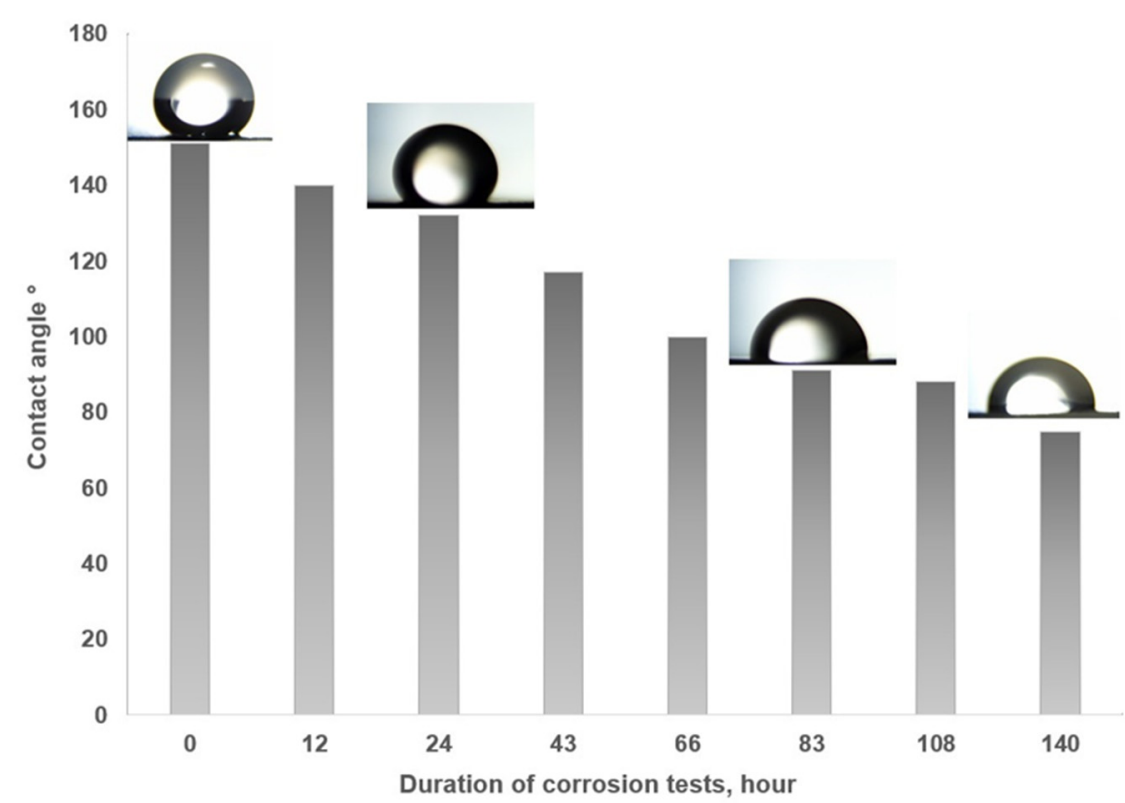

Figure 3. Plot of the wetting angle of a hydrophobized aluminum alloy versus the corrosion test duration in a salt fog chamber.

A

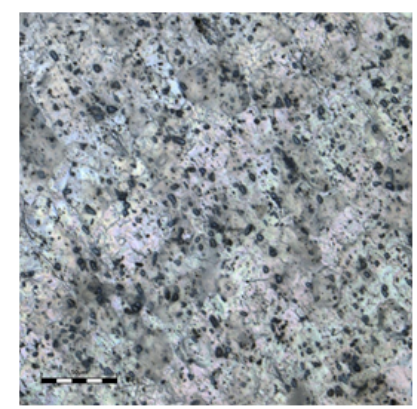

C

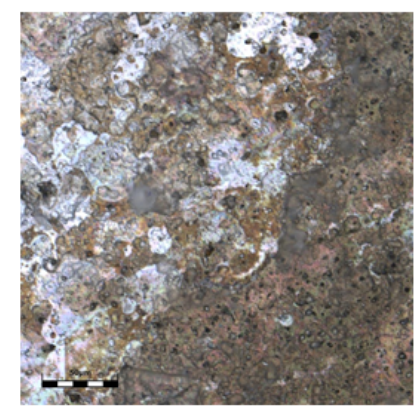

B

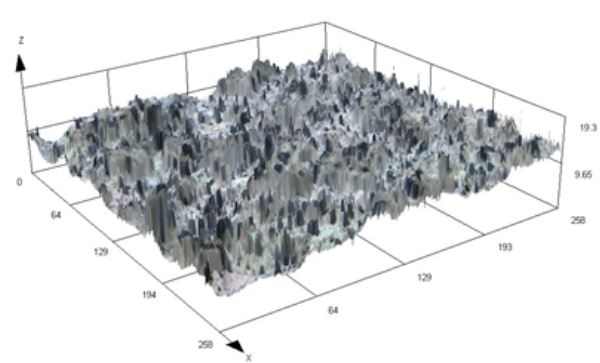

D

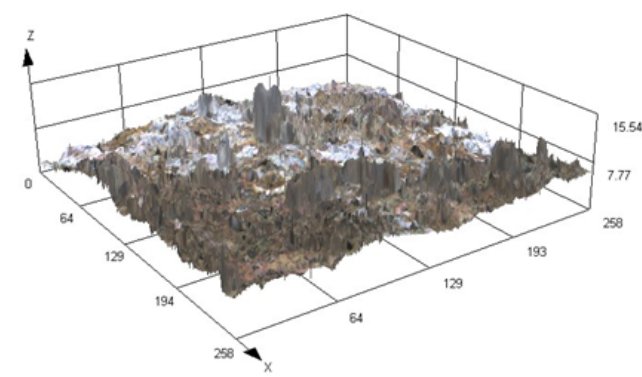

Figure 4. Micrographs of AMg6 alloy samples with the stearate coating applied: $(\mathbf{A}, \mathbf{B})$ - before corrosion tests; (C,D)-after corrosion tests.

A quantitative estimation of the protective effect of coatings formed on the surface of AMg6 alloy was also made using the drop-express method. Since the protective effect of a coating is determined in the drop-express method as the time required for $\mathrm{Cu}^{2+}$ ions to penetrate through it, plus the thickness of the layer formed is small and amounts to 270-300 $\mathrm{nm}$ according to spectroscopic ellipsometry data (DMSO: $\mathrm{H}_{2} \mathrm{O}=7: 1$ ), it may be assumed that the protective period $(\tau)$ changes almost linearly with the coating thickness $(\delta)$ according to Equation (1):

$$
\tau=\frac{\delta}{v(s)}
$$


where $v$ is the drift rate of $\mathrm{Cu}^{2+}$ cations to the alloy surface through the coating formed; $c$ is the concentration of stearic acid during the formation of the hydrophobic coating.

If we assume that the coating thickness is determined by the chemisorption of stearic acid according to the Langmuir Equation (2), then, taking into account (1), we obtain Equation (3):

$$
\begin{gathered}
A=\delta S \varphi=\frac{K c}{1+K c} \\
\tau=\frac{K c}{v(c) S \varphi(1+K c)}
\end{gathered}
$$

where $A$ is adsorption; $S$ is the surface area of the coating; $\varphi$ is the proportionality factor; $K$ is the constant of adsorption equilibrium.

If the value of $v(c)$ function is constant and does not depend on the concentration of stearic acid (c), then Equation (3) has the form (4) that is linear in the coordinates " $\frac{1}{\tau}$ vs. $\frac{1}{c}$ ".

$$
\frac{1}{\tau}=\frac{v(c) S \varphi}{K c}+v(c) S \varphi
$$

It has been shown that the protective period of the coating is a complex function of the composition of the binary system $\mathrm{DMSO} / \mathrm{H}_{2} \mathrm{O}$, stearic acid concentration, temperature, and duration of the coating process. As the $\mathrm{DMSO} / \mathrm{H}_{2} \mathrm{O}$ ratio decreases below $7: 1$, the protective period decreased, presumably due to the intensification of hydrolysis of aluminum stearate with an increase in the water concentration (Figure 5). At the same time, an increase in the DMSO $/ \mathrm{H}_{2} \mathrm{O}$ ratio above 7:1 probably results in a considerable decrease in the dissociation constant and degree of dissociation of stearic acid [50]. The plot of the protective period versus the concentration of stearic acid also manifests a pronounced extremum. On the one hand, a high concentration of stearic acid favors its chemisorption with the formation of aluminum stearate and an increase in the protective period. However, too high a concentration of stearic acid can favor its sorption on aluminum stearate (hydrophobic coating), which probably creates defects in the coating and an increase in its permeability (Figure 5).

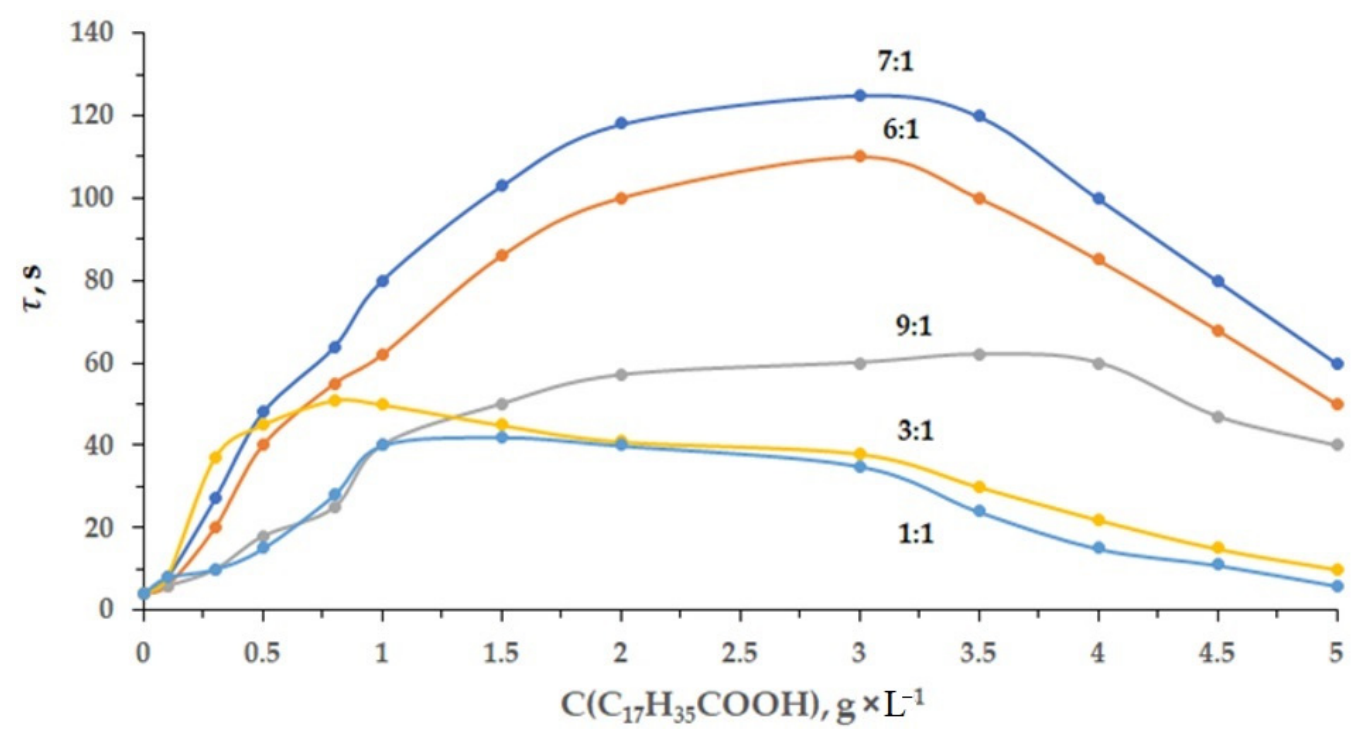

Figure 5. The protective periods of coatings formed at various concentrations of stearic acid in $\mathrm{DMSO} / \mathrm{H}_{2} \mathrm{O}$ binary mixtures with various compositions.

If the hydrophobic coating is sufficiently uniform (DMSO: $\mathrm{H}_{2} \mathrm{O}=7: 1$ ), a quantitative analysis of the effect of the concentration of stearic acid can be performed using Equation (4), which is derived in this article for the first time. Building the plot in the " $\frac{1}{\tau}$ vs. $\frac{1}{c}$ " coordinates (Figure 6) shows that the drift rate of $\mathrm{Cu}^{2+}$ cations to the surface of $\mathrm{AMg} 6$ alloy through the coating formed does not depend on the concentration of stearic acid up 
to $3 \mathrm{~g} \cdot \mathrm{L}^{-1}$ and increases at higher concentrations. Thus, an increase in the concentration of stearic acid above a certain value increases the permeability and decreases the protective effect of the coating. As one can see (Figure 5), for each of the coatings, there is a stearic acid concentration that provides the highest protective effect. Therefore, to achieve a high protective ability, one has to maintain a balance between the thickness of the deposited hydrophobic protective coating, which increases with an increase in the concentration of stearic acid to a certain limit, and the adsorption of stearic acid on the already formed coating that results in an increase in its permeability.

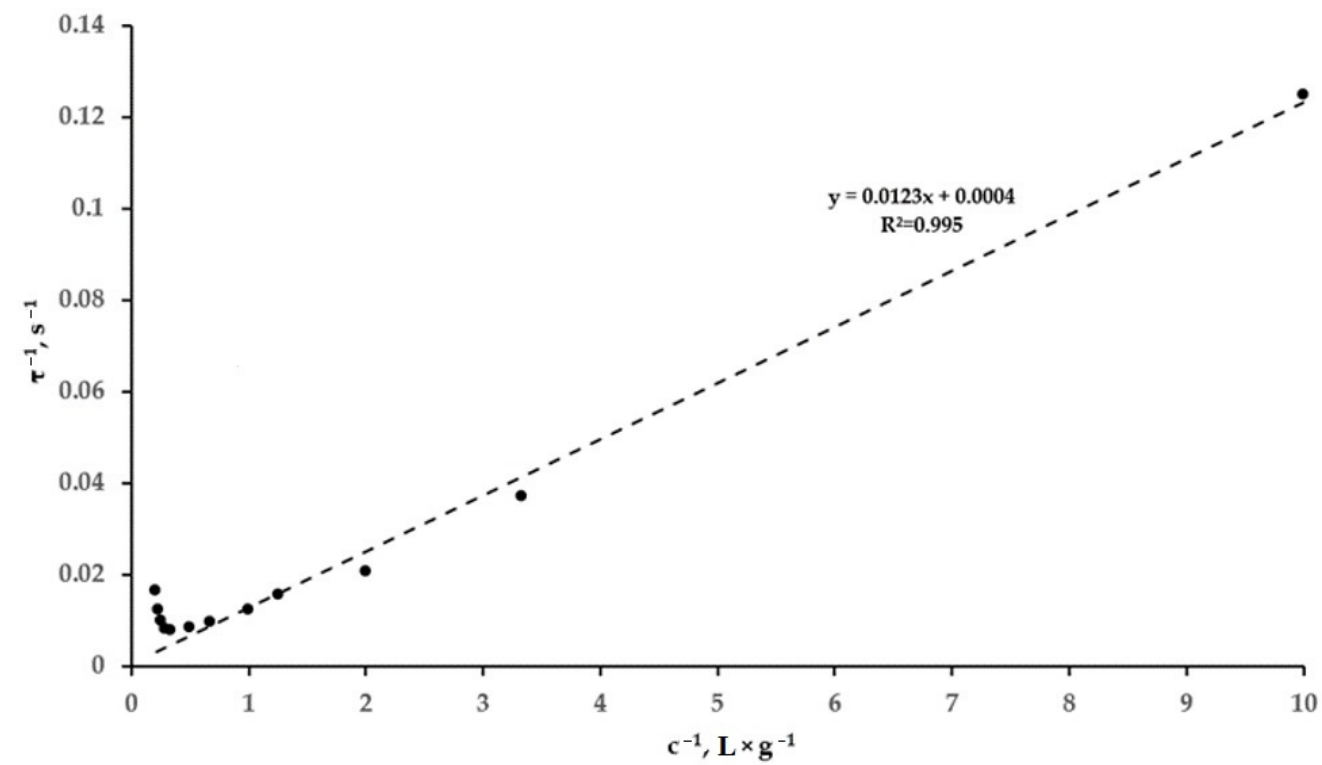

Figure 6. Plots in “ $\frac{1}{\tau}$ vs. $\frac{1}{c}$ " coordinates for coatings formed after AMg6 etching in $10 \mathrm{wt}^{\mathrm{w}} \%$ aqueous sodium hydroxide solution and hydrophobization with a stearic acid solution $\left(3 \mathrm{~g} \cdot \mathrm{L}^{-1}\right)$ in a DMSO $/ \mathrm{H}_{2} \mathrm{O}$ binary mixture $(7: 1 \mathrm{v} / \mathrm{v})$ at $30{ }^{\circ} \mathrm{C}$ for $10 \mathrm{~min}$.

The reason why the coating permeability increases with an increase in the concentration of stearic acid above $3 \mathrm{~g} \cdot \mathrm{L}^{-1}$ is that the latter is adsorbed on aluminum stearate, which is confirmed by a decrease in the protective period with an increase in the alloy hydrophobization time (Figure 7).

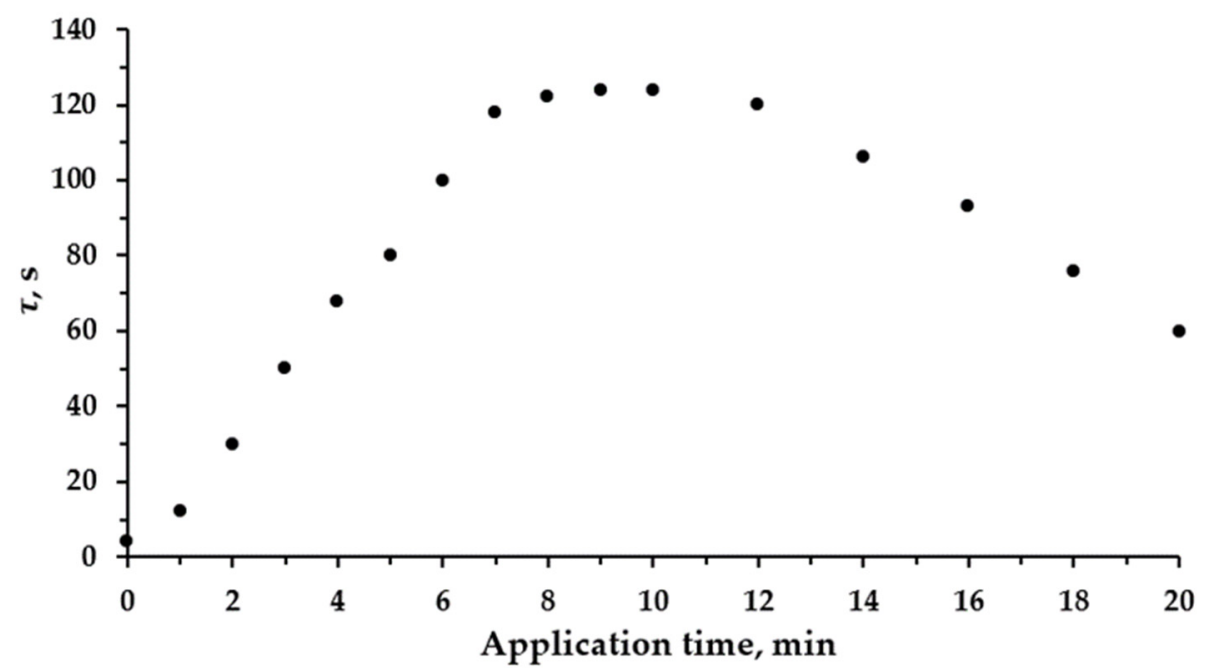

Figure 7. Time of the protective action of coatings formed after etching AMg6 alloy in $10 \mathrm{wt} \%$ aqueous solution of sodium hydroxide followed by hydrophobization with a stearic acid solution $\left(3 \mathrm{~g} \cdot \mathrm{L}^{-1}\right)$ in a DMSO$/ \mathrm{H}_{2} \mathrm{O}$ binary mixture $(7: 1 \mathrm{v} / \mathrm{v})$ at $40{ }^{\circ} \mathrm{C}$ for various modification times. 
The coating formation temperature also has a significant effect on the protective period. An increase in temperature simultaneously increases both the rate of aluminum stearate formation by the reaction of stearic acid with the surface of AMg6 alloy and its hydrolysis rate. The latter process determines the decrease in the protective period when the temperature rises above $30^{\circ} \mathrm{C}$ (Figure 8).

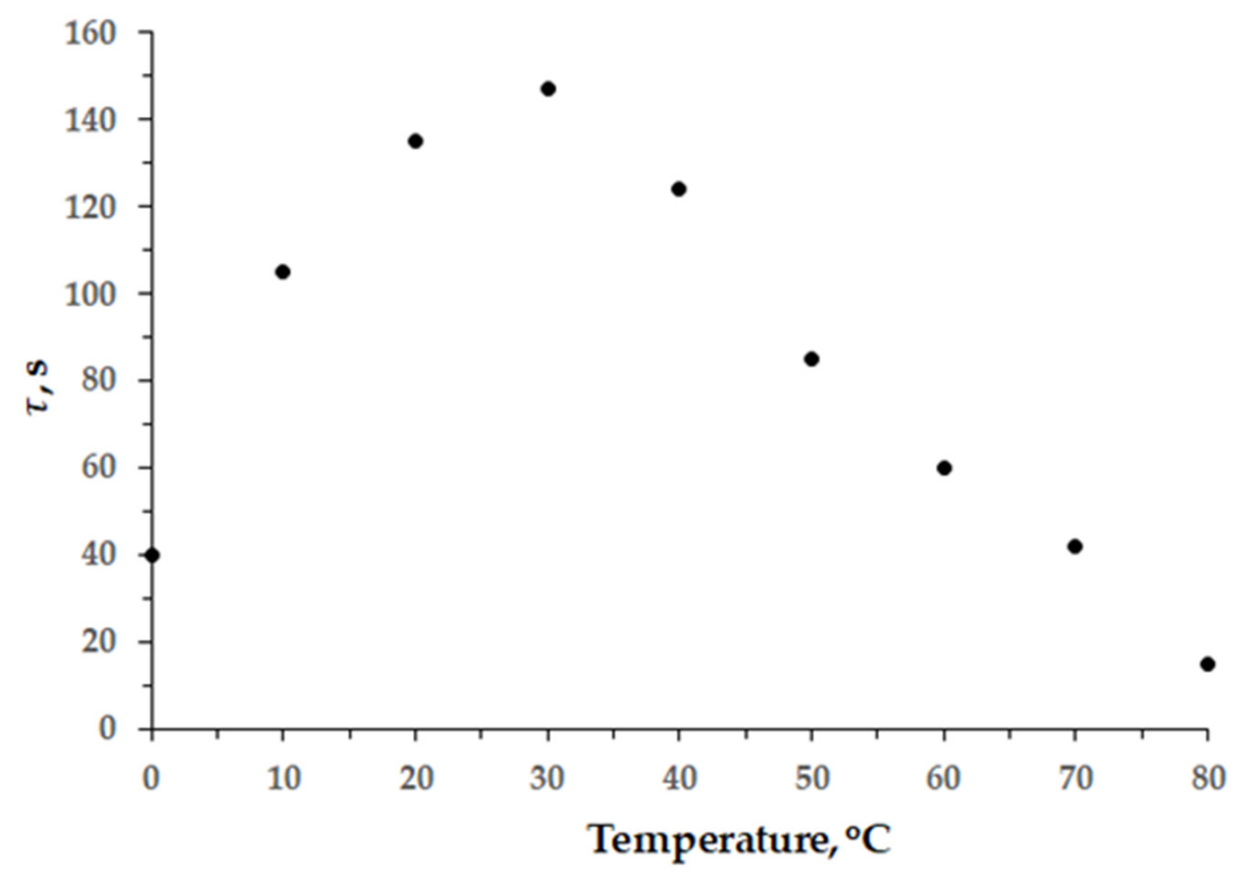

Figure 8. Protective period of coatings formed after AMg6 etching in $10 \mathrm{wt} \%$ aqueous sodium hydroxide solution followed by hydrophobization with a stearic acid solution $\left(3 \mathrm{~g} \cdot \mathrm{L}^{-1}\right)$ in a DMSO $/ \mathrm{H}_{2} \mathrm{O}$ binary mixture $(7: 1 \mathrm{v} / \mathrm{v})$ for $10 \mathrm{~min}$ at various temperatures.

Thus, the formation of protective superhydrophobic coatings on the surfaces of aluminum alloys requires that the temperature, stearic acid concentration, process duration, and proton-donating ability of the medium be controlled. The last can be adjusted by varying the DMSO $/ \mathrm{H}_{2} \mathrm{O}$ ratio, where an increase in the amount of DMSO leads to a decrease in the stearic acid dissociation. Previously, the use of DMF that belongs to the second hazard class as a co-solvent for hydrophobization of metal surfaces with stearic acid was reported [6]. In contrast, DMSO that belongs to the fourth hazard class is much less toxic [51-53] and is even recommended for pharmaceutical applications to provide an acceptable rate of transdermal drug delivery [54,55]. Therefore, the replacement of DMF with DMSO would help reduce the risks of poisoning, development of oncological diseases [56,57], and the impact on the environment if this approach to hydrophobization of the surfaces of metals and alloys were to be used on an industrial scale.

The stearate coating formed on the surface of the AMg6 aluminum alloy was tested for abrasion resistance. It has been shown that an increase in the number of abrasion cycles leads to a natural decrease in coating thickness (Figure 9A), contact angle (Figure 9B), and the protective ability of the coating (Figure 9C). At the same time, the coating has a sufficiently high resistance to mechanical stress and withstands at least 400 abrasion cycles while retaining a significant thickness, protective effect, and hydrophobicity (Figure 9).

Determination of the protective ability of the coating during its abrasion indicates the existence of a linear relationship between the protective ability of the coating and its thickness (Figure 10) and allows the calculation of the drift rate of $\mathrm{Cu}^{2+}$ cations to the alloy surface when testing the coating using the "droplet-express" method (Section 2.2), which is about $1.85 \mathrm{~nm} \cdot \mathrm{s}^{-1}$. 

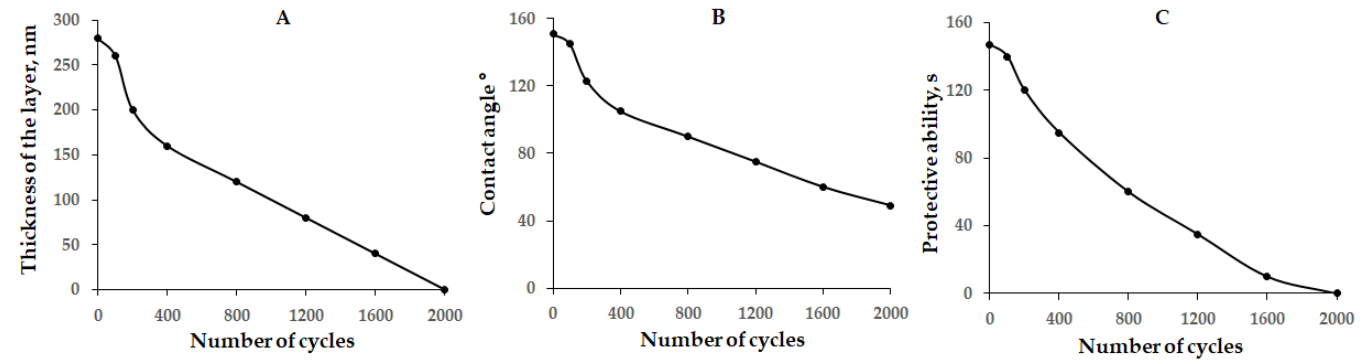

Figure 9. Dependence of the thickness of the stearate coating (A), contact angle (B), and protective ability $(\mathbf{C})$ on the number of abrasion cycles.

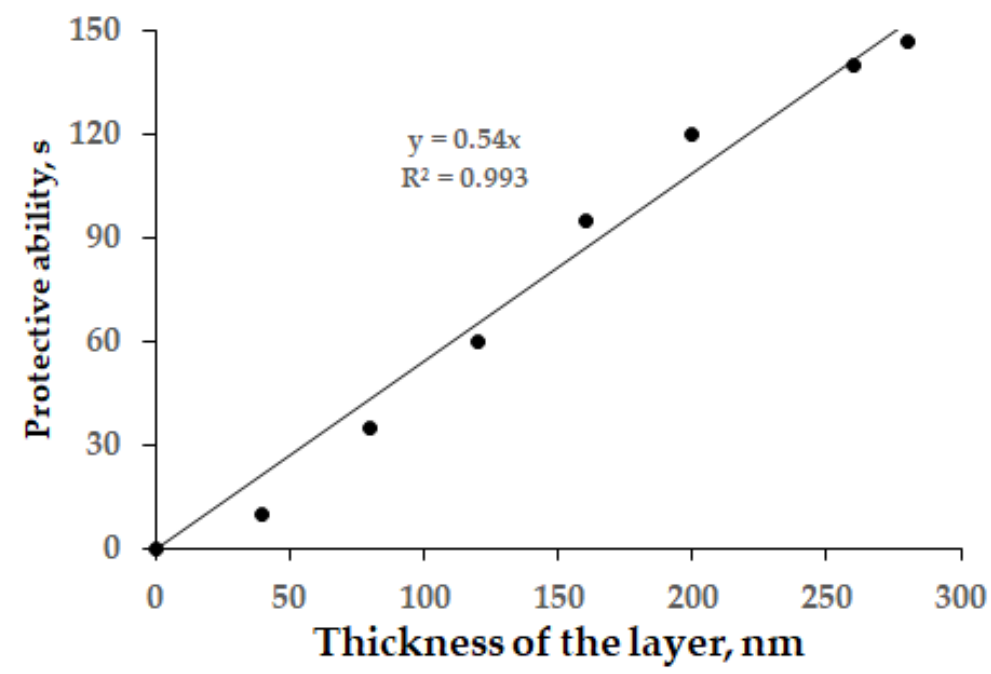

Figure 10. Correlation between the protective ability of the stearate coating on the surface of the AMg6 alloy and its thickness.

Thus, abrasion tests of the coating not only demonstrate its acceptable resistance to mechanical stress but also confirm the assumption that the drift rate of $\mathrm{Cu}^{2+}$ cations to the alloy surface through the stearate coating formed is constant, which is the basis for deriving Equation (4).

\section{Conclusions}

It was found that the treatment of the AMg6 aluminum alloy surface with stearic acid dissolved in the DMSO $/ \mathrm{H}_{2} \mathrm{O}$ binary system led to the formation of a hydrophobic coating; according to XPS data, this consists mainly of aluminum stearate. It was found that the reason for the decrease in the protective ability of the coating with an increase in the concentration of stearic acid in the binary system $\mathrm{DMSO} / \mathrm{H}_{2} \mathrm{O}$ over $3 \mathrm{~g} \cdot \mathrm{L}^{-1}$ was its adsorption on aluminum stearate. Additionally, in order to achieve the maximum protective ability of the stearate coating, an optimal DMSO $/ \mathrm{H}_{2} \mathrm{O}$ ratio of about 7:1 and a temperature of $20-30{ }^{\circ} \mathrm{C}$ are required. An increase in the DMSO content leads to a decrease in the proton-donating ability of the medium, whereas an increase in the concentration of water and temperature above certain values leads to the development of hydrolysis of aluminum stearate. The possibility of using the treatment of the aluminum alloy with stearic acid for the formation of a superhydrophobic coating with a contact angle of $151^{\circ}$, subject to the optimal application conditions and the roughness of the original metal surface obtained as a result of alkaline etching, is shown. The stearate coating formed is characterized by a roll-off angle of water of $7^{\circ}$, which indicates its ability for self-cleaning. It was found that the stearate coating had acceptable resistance to mechanical stress and retained its protective ability after 400 abrasion cycles as well as its hydrophobicity after exposure to salt fog for $80 \mathrm{~h}$. The developed approach to the formation of the protective 
coating implies the possibility of multiple uses of the low-toxic working stearic acid solutions, which allows this to be classified as a green method.

Author Contributions: Conceptualization, A.A., N.G. and Y.M.; formal analysis, Y.M.; methodology, A.A., N.G., Y.K., T.V. and O.G.; validation, T.V. and N.G.; investigation, A.A., N.G., Y.K., T.V. and O.G.; resources, T.V. and A.A.; writing-original draft preparation, A.A., N.G. and Y.M.; writing-review and editing, Y.K., T.V., O.G. and Y.M.; visualization, A.A. and Y.M. All authors have read and agreed to the published version of the manuscript.

Funding: The work was supported by the Mendeleev University of Chemical Technology of Russia. Project Number X-2020-028.

Institutional Review Board Statement: Not applicable.

Informed Consent Statement: Not applicable.

Data Availability Statement: The data presented in this study are available on request from the corresponding author.

Acknowledgments: Our special thanks to A.N. Frumkin Institute of Physical Chemistry and Electrochemistry of the Russian Academy of Sciences (IPCE RAS) for assistance in obtaining XPS spectra images.

Conflicts of Interest: The authors declare no conflict of interest.

\section{References}

1. Erbil, H.Y. Practical applications of superhydrophobic materials and coatings: Problems and perspectives. Langmuir 2020, 36, 2493-2509. [CrossRef]

2. Simpson, J.T.; Hunter, S.R.; Aytug, T. Superhydrophobic materials and coatings: A review. Rep. Prog. Phys. 2015, 78, 086501. [CrossRef]

3. Boinovich, L.B.; Emelyanenko, A.M. Hydrophobic materials and coatings: Principles of design, properties and applications. Russ. Chem. Rev. 2008, 77, 583-600. [CrossRef]

4. Jeevahan, J.; Chandrasekaran, M.; Joseph, B.G.; Durairaj, R.B.; Mageshwaran, G. Superhydrophobic surfaces: A review on fundamentals, applications, and challenges. J. Coat. Technol. Res. 2018, 15, 231-250. [CrossRef]

5. Drelich, J.W.; Boinovich, L.; Chibowski, E.; Della Volpe, C.; Hołysz, L.; Marmur, A.; Siboni, S. Wetting angles: History of over 200 years of open questions. Surf. Innov. 2020, 8, 3-27. [CrossRef]

6. Zang, D.; Zhu, R.; Zhang, W.; Wu, J.; Yu, X.; Zhang, Y. Stearic acid modified aluminum surfaces with controlled wetting properties and corrosion resistance. Corros. Sci. 2014, 83, 86-93. [CrossRef]

7. Boinovich, L.B.; Emelyanenko, A.M.; Modestov, A.D.; Domantovsky, A.G.; Emelyanenko, K.A. Not simply repel water: The diversified nature of corrosion protection by superhydrophobic coatings. Mendeleev Commun. 2017, 27, 254-256. [CrossRef]

8. Kuznetsov, Y.I.; Semiletov, A.M.; Chirkunov, A.A.; Arkhipushkin, I.A.; Kazanskii, L.P.; Andreeva, N.P. Protecting aluminum from atmospheric corrosion via surface hydrophobization with stearic acid and trialkoxysilanes. Russ. J. Phys. Chem. A 2018, 92, 621-629. [CrossRef]

9. Ferrari, M.; Benedetti, A. Superhydrophobic surfaces for applications in seawater. Adv. Colloid Interface Sci. 2015, 222, 291-304. [CrossRef]

10. Boinovich, L.B.; Gnedenkov, S.V.; Alpysbaeva, D.A.; Egorkin, V.S.; Emelyanenko, A.M.; Sinebryukhov, S.L.; Zaretskaya, A.K. Corrosion resistance of composite coatings on low-carbon steel containing hydrophobic and superhydrophobic layers in combination with oxide sublayers. Corros. Sci. 2012, 55, 238-245. [CrossRef]

11. Liu, M.; Hou, Y.; Li, J.; Tie, L.; Peng, Y.; Guo, Z. Inorganic adhesives for robust, self-healing, superhydrophobic surfaces. J. Mater. Chem. A 2017, 5, 19297-19305. [CrossRef]

12. Golovin, K.; Boban, M.; Mabry, J.M.; Tuteja, A. Designing self-healing superhydrophobic surfaces with exceptional mechanical durability. ACS Appl. Mater. Interfaces 2017, 9, 11212-11223. [CrossRef]

13. Conde, J.J.; Ferreira-Aparicio, P.; Chaparro, A.M. Anti-corrosion coating for metal surfaces based on superhydrophobic electro sprayed carbon layers. Appl. Mater. Today 2018, 13, 100-106. [CrossRef]

14. Nguyen-Tri, P.; Tran, H.N.; Plamondon, C.O.; Vo, D.V.N.; Nanda, S.; Mishra, A.; Chao, H.P.; Bajpai, A.K. Recent progress in the preparation, properties and applications of superhydrophobic nano-based coatings and surfaces: A review. Prog. Org. Coat. 2019, 132, 235-256. [CrossRef]

15. Esteves, C. Self-healing functional surfaces. Adv. Mater. Interfaces 2018, 5, 1800293. [CrossRef]

16. Lin, Y.; Chen, H.; Wang, G.; Liu, A. Recent progress in preparation and anti-icing applications of superhydrophobic coatings. Coatings 2018, 8, 208. [CrossRef]

17. Ozbay, S.; Yuceel, C.; Erbil, H.Y. Improved icephobic properties on surfaces with a hydrophilic self-lubricating liquid. ACS Appl. Mater. Interfaces 2015, 7, 22067-22077. [CrossRef] 
18. Khedir, K.R.; Kannarpady, G.K.; Ryerson, C.; Birisa, A.S. An outlook on tunable superhydrophobic nanostructural surfaces and their possible impact on ice mitigation. Prog. Org. Coat. 2017, 112, 304-318. [CrossRef]

19. Abrashov, A.A.; Grigoryan, N.S.; Tolmachev, Y.V.; Serov, A.N. Environmentally friendly solution of hydrophobization of the 5556 alloy based on stearic acid and dimethyl sulfoxide. Tsvetnye Metally 2021, 10, 37-42.

20. Nguyen, T.B.; Park, S.; Lim, H. Effects of morphology parameters on anti-icing performance in superhydrophobic surfaces. Appl. Surf. Sci. 2018, 435, 585-591. [CrossRef]

21. Zheng, S.; Fu, Q.; Hu, W.; Li, C.; Xiang, T.; Wang, Q.; Du, M.; Liu, X.; Chen, Z. Development of stable superhydrophobic coatings on aluminum surface for corrosion-resistant, self-cleaning, and anti-icing applications. Mater. Des. 2016, 93, 261-270. [CrossRef]

22. Boinovich, L.B.; Modin, E.B.; Sayfutdinova, A.R.; Emelyanenko, K.A.; Vasiliev, A.L.; Emelyanenko, A.M. Combination of Functional Nanoengineering and Nanosecond Laser Texturing for Design of Superhydrophobic Aluminum Alloy with Exceptional Mechanical and Chemical Properties. ACS Nano 2017, 11, 10113-10123. [CrossRef]

23. Zhu, J. A novel fabrication of superhydrophobic surfaces on aluminum substrate. Appl. Surf. Sci. 2018, 447, 363-367. [CrossRef]

24. Lu, Z.; Wang, P.; Zhang, D. Super-hydrophobic film fabricated on aluminium surface as a barrier to atmospheric corrosion in a marine environment. Corros. Sci. 2015, 91, 287-296. [CrossRef]

25. Marmur, A.; Della Volpe, C.; Siboni, S.; Amirfazli, A.; Drelich, J.W. Wetting angles and wettability: Towards common and accurate terminology. Surf. Innov. 2017, 5, 3-8. [CrossRef]

26. Vazirinasab, E.; Jafari, R.; Momen, G. Application of superhydrophobic coatings as a corrosion barrier: A review. Surf. Coat. Technol. 2018, 341, 40-56. [CrossRef]

27. Erbil, H.Y. Dependency of Wetting angles on Three-Phase Contact Line: A Review. Colloids Interfaces 2021, 5, 8. [CrossRef]

28. Drelich, J.W. Wetting angles: From past mistakes to new developments through liquid-solid adhesion measurements. Adv. Colloid Interface Sci. 2019, 267, 1-14. [CrossRef] [PubMed]

29. Mokhtari, S.; Karimzadeh, F.; Abbasi, M.H.; Raeissi, K. Development of super-hydrophobic surface on Al 6061 by anodizing and the evaluation of its corrosion behavior. Surf. Coat. Technol. 2017, 324, 99-105. [CrossRef]

30. Zheng, S.; Li, C.; Zhang, Y.; Xiang, T.; Cao, Y.; Li, Q.; Chen, Z. A General Strategy towards Superhydrophobic Self-Cleaning and Anti-Corrosion Metallic Surfaces: An Example with Aluminum Alloy. Coatings 2021, 11, 788. [CrossRef]

31. Ruan, M.; Wang, J.W.; Liu, Q.L.; Ma, F.M.; Yu, Z.L.; Feng, W.; Chen, Y. Superhydrophobic and anti-icing properties of sol-gel prepared alumina coatings. Russ. J. Non-Ferr. Met. 2016, 57, 638-645. [CrossRef]

32. Czyzyk, S.; Dotan, A.; Dodiuk, H.; Kenig, S. Processing effects on the kinetics morphology and properties of hybrid sol-gel superhydrophobic coatings. Prog. Org. Coat. 2020, 140, 105501. [CrossRef]

33. Czyzyk, S.; Dotan, A.; Dodiuk, H.; Kenig, S. Easy-to-Clean Superhydrophobic Coatings Based on Sol-Gel Technology: A Critical Review. Rev. Adhes. Adhes. 2017, 5, 325-360. [CrossRef]

34. Volpe, A.; Gaudiuso, C.; Ancona, A. Laser Fabrication of Anti-Icing Surfaces: A Review. Materials 2020, 13, 5692. [CrossRef] [PubMed]

35. Emelyanenko, K.A.; Domantovsky, A.G.; Chulkova, E.V.; Emelyanenko, A.M.; Boinovich, L.B. Thermally Induced Gradient of Properties on a Superhydrophobic Magnesium Alloy Surface. Metals 2021, 11, 41. [CrossRef]

36. Zhao, L.; Liu, Q.; Gao, R.; Wang, J.; Yang, W.; Liu, L. One-step method for the fabrication of superhydrophobic surface on magnesium alloy and its corrosion protection, antifouling performance. Corros. Sci. 2014, 80, 177-183. [CrossRef]

37. Abohalkuma, T.; Shawish, F.; Telegdi, J. Phosphonic acid derivatives used in self assembled layers against metal corrosion. Int. J. Corros. Scale Inhib. 2014, 3, 151-159. [CrossRef]

38. Abrashov, A.A.; Grigoryan, N.S.; Vagramyan, T.A.; Simonova, M.A.; Miroshnikov, V.S.; Arkhipushkin, I.A. Surface passivation of 5556 aluminum alloy in solutions based on cerium nitrate. Int. J. Corros. Scale Inhib. 2021, 10, 132-144.

39. Bold, A.; Sassykova, L.; Fogel, L.; Vagramyan, T.; Abrashov, A. Influence of Molybdenum and Tungsten on the Formation of Zirconium Oxide Coatings on a Steel Base. Coatings 2021, 11, 42. [CrossRef]

40. Abrashov, A.; Grigoryan, N.; Vagramyan, T.; Asnis, N. On the Mechanism of Formation of Conversion Titanium-Containing Coatings. Coatings 2020, 10, 328. [CrossRef]

41. Laha, P.; Schram, T.; Terry, H. Use of spectroscopic ellipsometry to study Zr/Ti films on Al. Surf. Interface Anal. 2002, 34, 677-680. [CrossRef]

42. Woicik, J.C. Hard X-ray Photoelectron Spectroscopy (HAXPES); Springer International Publishing: Cham, Switzerland, 2016 ; p. 571.

43. Shirley, D.A. High-resolution X-ray photoemission spectrum of the valence bands of gold. Phys. Rev. 1972, 5, 4709-4713. [CrossRef]

44. Scofield, H.; Hartree-Slater, J. Subshell photoionization cross-sections at 1254 and 1487 eV. Electron Spectrosc. Relat. Phenom. 1976, 8, 129-137. [CrossRef]

45. Mohai, M. XPS MultiQuant: Multimodel XPS quantification software. Surf. Interface Anal. 2004, 36, 828-832. [CrossRef]

46. Cumpson, P.J.; Seah, M.P. Elastic scattering corrections in AES and XPS. II. Estimating attenuation lengths and conditions required for their valid use in Overlayer/Substrate experiments. Surf. Interface Anal. 1997, 25, 430-446. [CrossRef]

47. Ciucanu, C.I.; Vlad, D.C.; Ciucanu, I.; Dumitraşcu, V. Selective and fast methylation of free fatty acids directly in plasma for their individual analysis by gas chromatography-mass spectrometry. J. Chromatogr. A 2020, 1624, 461259. [CrossRef]

48. Seal, S.; Krezoski, S.; Barr, T.L.; Petering, D.H.; Klinowski, J.; Evans, P.H. Surface chemistry and biological pathogenicity of silicates: An X-ray photoelectron spectroscopic study. Proc. R. Soc. Lond. B 1996, 263, 943-951. 
49. Kendig, M.W.; Buchheit, R.G. Corrosion Inhibition of Aluminum and Aluminum Alloys by Soluble Chromates, Chromate Coatings, and Chromate-Free Coatings. CORROSION 2003, 59, 379-399. [CrossRef]

50. Jaishankar, A.; Jusufi, A.; Vreeland, J.L.; Deighton, S.; Pellettiere, J.; Schilowitz, A.M. Adsorption of Stearic Acid at the Iron Oxide/Oil Interface: Theory, Experiments, and Modeling. Langmuir 2019, 35, 2033-2046. [CrossRef] [PubMed]

51. Wang, Z.; Richter, S.M.; Bellettini, J.R.; Yu-M, P.; Hill, D.R. Safe Scale-Up of Pharmaceutical Manufacturing Processes with Dimethyl Sulfoxide as the Solvent and a Reactant or a Byproduct. Org. Process Res. Dev. 2014, 18, 1836-1842. [CrossRef]

52. Tian, Y.; Zhang, X.; Yu, B.; Bai, Y.; Guan, L.; Teng, S.; Li, J.; Huang, C.; Lanz, M.; Hoehn, P. Case-Based Thermal Safety Evaluation on a Pharmaceutical Process Using Dimethyl Sulfoxide as a Solvent. Org. Process Res. Dev. 2020, 24, 2927-2934. [CrossRef]

53. Wang, M.; Dong, X.; Escobar, I.C.; Cheng, Y.-T. Lithium Ion Battery Electrodes Made Using Dimethyl Sulfoxide (DMSO)-A Green Solvent. ACS Sustain. Chem. Eng. 2020, 8, 11046-11051. [CrossRef]

54. Capriotti, K.; Capriotti, J.A. Dimethyl Sulfoxide. History, Chemistry, and Clinical Utility in Dermatology. J. Clin. Aesthet. Dermatol. 2012, 5, 24-26. [PubMed]

55. Yuan, Y.; Choi, K.; Choi, S.-O.; Kim, J. Early stage release control of an anticancer drug by drug-polymer miscibility in a hydrophobic fiber-based drug delivery system. RSC Adv. 2018, 8, 19791-19803. [CrossRef]

56. Yoon, J.H.; Yoo, C.I.; Ahn, Y.S. N,N-dimethylformamide: Evidence of carcinogenicity from national representative cohort study in South Korea. Scand. J. Work Environ. Health 2019, 45, 396-401. [CrossRef] [PubMed]

57. Senoh, H.; Aiso, S.; Arito, H.; Nishizawa, T.; Nagano, K.; Yamamoto, S.; Matsushima, T. Carcinogenicity and chronic toxicity after inhalation exposure of rats and mice to N,N-dimethylformamide. J. Occup. Health 2004, 46, 429-439. [CrossRef] [PubMed] 